\title{
NUCLEAR BURNING WAVE CONCEPT AND THEORETICAL APPROACHES FOR ITS DESCRIPTION
}

\author{
(D)Maksym S. Malovytsia ${ }^{\mathrm{a}, *}$, (D)Alex S. Fomin ${ }^{\mathrm{b}}$, (D)Sergii P. Fomin ${ }^{\mathrm{a}, \mathrm{b}, \dagger}$ \\ ${ }^{a}$ V.N. Karazin Kharkiv National University \\ 4, Svobody sq., 61022, Kharkiv, Ukraine \\ ${ }^{b}$ National Science Center "Kharkov Institute of Physics and Technology" \\ 1, Akademichna str., Kharkiv, Ukraine, 61108 \\ $\dagger$ E-mail:sfomin@kipt.kharkov.ua \\ *Corresponding Author: jcm2027@gmail.com \\ Received June 15, 2020; accepted June 30, 2020
}

\begin{abstract}
After two major nuclear power plant accidents in Chernobyl (1986) and Fukushima (2011), one of the main requirements for the nuclear power engineering is the safety of the nuclear reactors in operation, as well as new nuclear power plants of the fourth generation, which are being developed now. One of such requirements is presence of the so-called "inherent safety" mechanism, which renders the uncontrolled reactor runaway impossible under any conditions, moreover, the implementation of such a mechanism should be ensured on the level of physical principles embedded in the reactor design. Another important problem of the nuclear power engineering is the need of the transition to the large-scale use of the fast-neutron breeder reactors, with which it would be possible to set up expanded reproduction of the nuclear fuel and by that means solve the problem of supplying humanity with relatively cheap energy for thousands of years. Moreover, at present an unresolved problem is the disposal of spent nuclear fuel containing radioactive nuclides with long half-lives, which presents a long-term danger to the ecology. One of the promising conceptions of the fast-neutron breeder reactor, which can, in the case of successful implementation, partially or even entirely solve the problems of the nuclear power engineering mentioned above, is the reactor that operates in the nuclear burning wave mode, which is also known as "Traveling wave reactor", CANDLE and by some other names. This paper presents a short review of the main theoretical approaches used for description of such a physical phenomenon as slow nuclear burning (deflagration) wave in the neutron multiplication medium initially composed of the fertile material ${ }^{238} \mathrm{U}$ or ${ }^{232} \mathrm{Th}$. A comparative analysis of the possibilities of different mathematical models for describing this phenomenon is performed, both for those based on the deterministic approach (i.e. solving neutron transport equations) and for models that use Monte Carlo methods. The main merits of the fast breeder reactor, working in the nuclear burning wave mode, and problems related to the practical realization of the considered concept are discussed.

KEY WORDS: nuclear power, fast reactor, breed and burn, nuclear burning wave, traveling wave reactor
\end{abstract}

The fast growth of the planet population along with the general striving for more comfortable life leads to the rapid increase of the world energy consumption. As a matter of fact, with the doubling of the human population over the past 50 years, the total global energy consumption has increased three times. In the face of the limited Earth resources of conventional energy sources, such as coal, oil, gas, there arises more urgently a problem of searching for new alternative energy sources. Moreover, the widespread use of the combustible carbon-based fuel in the industry, transport and in everyday life leads to the catastrophic environment pollution with carbon dioxide $\left(\mathrm{CO}_{2}\right.$ problem $)$ and other toxic emissions. Apart from the direct influence on the people's health and environment, this leads to the greenhouse effect, which is probably one of the causes of global climate change. All of this urges scientists to look for new reliable, clean, preferably renewable energy sources that can support sustainable development of humanity for a long time.

As far back as the middle of the previous century the mankind discovered an absolutely novel source of energy with the incomparable power, namely, the energy of atomic nucleus. By the colossal efforts of leading scientists of several countries, in a quite short period not only the problem of releasing this energy was solved but also the possibility was found to use it as a controlled process in nuclear power plants and other installations. However, despite the high efficiency, the nuclear energy has not become the primary energy source of humanity. At present, its share is less than $5 \%$ in the total energy production and slightly more than $10 \%$ in the production of electricity.

The main reason behind the rather meager usage of the nuclear energy in the world, as well as the complete rejection of its usage in some countries, is not technological problems, but rather problems of psychological nature, caused by radiophobia, which swept the world after two major accidents of nuclear power plants: Chernobyl (1986) and Fukushima (2011). Analysis of the causes of those accidents has shown that, with responsible approach to the designing and operation of the nuclear power plants and training of the staff, this type of accidents should not be possible. The result of this analysis was a considerable increase in the requirements for the safety of the nuclear reactors in operation, as well as new nuclear power plants of the fourth generation that are being developed now. One of such requirements is the presence of the so-called "inherent safety" mechanism, which renders the uncontrolled reactor runaway impossible under any conditions, moreover, the implementation of this mechanism should be performed on the level of physical principles, which should be laid down in the reactor construction.

From the physics point of view, the most concentrated energy source, which can be practically utilized, is the binding energy of nucleons in the atom and its nature is due to the strong interaction. For one act of the nucleus fission 
the energy released equals to approximately two hundred millions of electron-volts. For comparison, the energy released in the process of carbon oxidation, $\mathrm{C}+\mathrm{O}_{2}=\mathrm{CO}_{2}$, is equal to several electron-volts. The carbon oxidation process or "chemical burning", which is the essence of the "combustion energy", has its origins in the electromagnetic interaction between electron shells of the atoms. As can be seen, the difference of the energy release per atom between nuclear and chemical reactions is almost eight orders in favour of the nuclear ones.

Recently, the so-called renewable energy sources, which include hydropower, wind power, solar power, and biofuel, have been growing in popularity. The highest share of the renewables in the total energy balance belongs to hydropower (approximately 7\%). The hydropower is based on the mechanical energy of water falling in the gravitational field. It is well known that the gravitational constant is rather small, therefore a large amount of the "working medium" (water) is required to get considerable quantities of energy. The same goes for the wind power generators.

Let us compare the efficiency of different kinds of energy sources in terms of the concentrations of stored energy that can be utilized by human. From $1 \mathrm{~cm}^{3}$ of the pure ${ }^{235} \mathrm{U}$, theoretically, i.e. by the fission of all the nuclei present in this volume, the energy of $5 \cdot 10^{5} \mathrm{~kW} \cdot \mathrm{h}$ can be released, which is equivalent of the energy released by the combustion of $100 \mathrm{~m}^{3}$ of anthracite coal or by dropping 100 millions of $\mathrm{m}^{3}$ of water from the height of $25 \mathrm{~m}$.

Thus, theoretically, the nuclear power should undoubtedly be leading in terms of efficiency among other types of Earth resources. However, the high density of the energy release of the nuclear chain reaction requires a high technological culture of controlling such processes. The principal possibilities and main technical solutions of the problems, related to the nuclear reactor control, were discovered as far back as middle of the past century. However, the accumulated world experience in the operation of nuclear power plants, both positive and negative, indicates the need to revise priorities in this area from maximum economy to the safety.

The history of nuclear power goes back a little over 70 years. In many countries, this is an important component in energy production, and in several of them, such as France, Ukraine, Belgium, Hungary, Slovakia, it plays the decisive role. Some of the rapidly developing countries, such as China, India, Russia, South Korea, have plans of accelerated construction of new nuclear power plants. At the same time, some developed countries, such as Belgium, Germany, Spain, Italy, Switzerland, Sweden, have decided to gradually remove the use of nuclear power. The last-mentioned fact is caused by the wave of radiophobia which swept the world after three major nuclear power plants accidents: Three Mile Island (1979), Chernobyl (1986), and Fukushima (2011), especially due to the last two. An important lesson learned from those accidents was the radical revision of the safety requirements for the nuclear systems. In particular, IAEA has formulated general requirements for the nuclear power plants of new generation, where one of the most important requirements is to ensure the so-called "inherent safety" property, which would exclude the possibility of uncontrolled reactor runaway owing to any of the internal or external influences, including operator's mistake.

Another important problem in the nuclear energy is the limited natural resources of ${ }^{235} \mathrm{U}$, which is the main component of nuclear fuel of the thermal nuclear reactors, which are a majority among the 449 working power plants and those 54 that are being built. The solution of this problem lies in the need of a large-scale transition to the fast neutron breeder reactors, in which, in addition to the energy production, artificial fissile products, such as ${ }^{239} \mathrm{Pu}$ and ${ }^{233} \mathrm{U}$, can also be produced from the natural ${ }^{238} \mathrm{U}$ and ${ }^{232} \mathrm{Th}$, respectively. In this way, by means of the production of fuel for new reactors in the fast-neutron breeder reactors, the nuclear power could be considered as a renewable energy source in the future.

Another not yet resolved problem in nuclear energy is the recycling of the spent nuclear fuel. Certainly, the volumes of the nuclear waste are by orders smaller than waste volumes of usual "combustion" energy. However, some of the radioactive components of a spent nuclear fuel, mainly the transuranium elements (minor actinides, MAs), have quite large half-times (thousands of years) and present a certain danger to the future generations if stored in large quantities. In this connection, an important direction of studies in the nuclear energy field is the problem of disposal of the long-lived radioactive isotopes.

The focus of this paper is on one of the promising concepts of a fast-neutron breeder reactor (FR) that works in the nuclear burning wave (NBW) mode, which, if successfully implemented, will solve partly or even entirely the problems of the nuclear energy discussed above. The purpose of this paper is to concisely describe the physical basis of the considered concept and to perform a comparative analysis of different mathematical models used for describing this NBW phenomenon, both those based on the deterministic approach (i.e. solving the neutron transport equations) and the models using Monte Carlo methods. Different theoretical approaches are presented in this paper in the chronological order. The main merits of the NBW reactor and problems related to its implementation are discussed.

\section{NUCLEAR BURNING WAVE CONCEPT}

The idea of a fast breeder reactor in which the process of production and burnup of fissile nuclides takes place with the continuous supply of fertile ${ }^{238} \mathrm{U}$ fuel and withdrawal of fission products was mentioned for the first time by the Soviet academician S.M. Feinberg during discussing the reports on the fast reactors at the II International UN conference dedicated to the peaceful usage of the atomic energy (September 1958, Geneva, Switzerland) [1]. The criticality of such reactor is maintained by means of plutonium accumulation in the reactor. However, as was noted by S.M. Feinberg, lack of knowledge about the precise dependence of the cross-section values on the energy for the fast 
neutrons did not allow accurate calculations of such a reactor. Furthermore, the fuel elements, being able to withstand a sufficiently large fuel burnup, which could reach up to $30 \%$ by the theoretical estimations of E.P. Kunegin [1], were not available at that time.

In search of the concept of safe nuclear reactor after the Chernobyl accident, another soviet academician L.P. Feoktistov [2,3] considered the possibility of a self-sustaining and self-controlled mode of propagation of a nuclear chain reaction in a medium filled with fertile material (for example, ${ }^{238} \mathrm{U}$ ) in the form of a traveling wave. He called this phenomenon as the neutron-fission wave. The phenomenon consists in the gradual movement of the reactor core area, in which the chain reaction takes place, into the breeding zone, in which, under the neutron irradiation, the production and accumulation of fissile nuclides (plutonium in such a case) occurs. When the concentration of plutonium in the breeding region reaches a critical value, the conditions for the development of nuclear chain reaction are realized in it, and the nuclear burning process also captures this region. At the same time, at the site of the previous active zone, the chain reaction gradually extinguishes as a result of depletion of fertile material and the accumulation of a large number of fission products that intensively absorb neutrons and thereby suppress the chain reaction in this region. The physical picture of the nuclear burning wave (NBW) propagation through the medium filled with initially pure ${ }^{238} \mathrm{U}$ is represented in Figure.

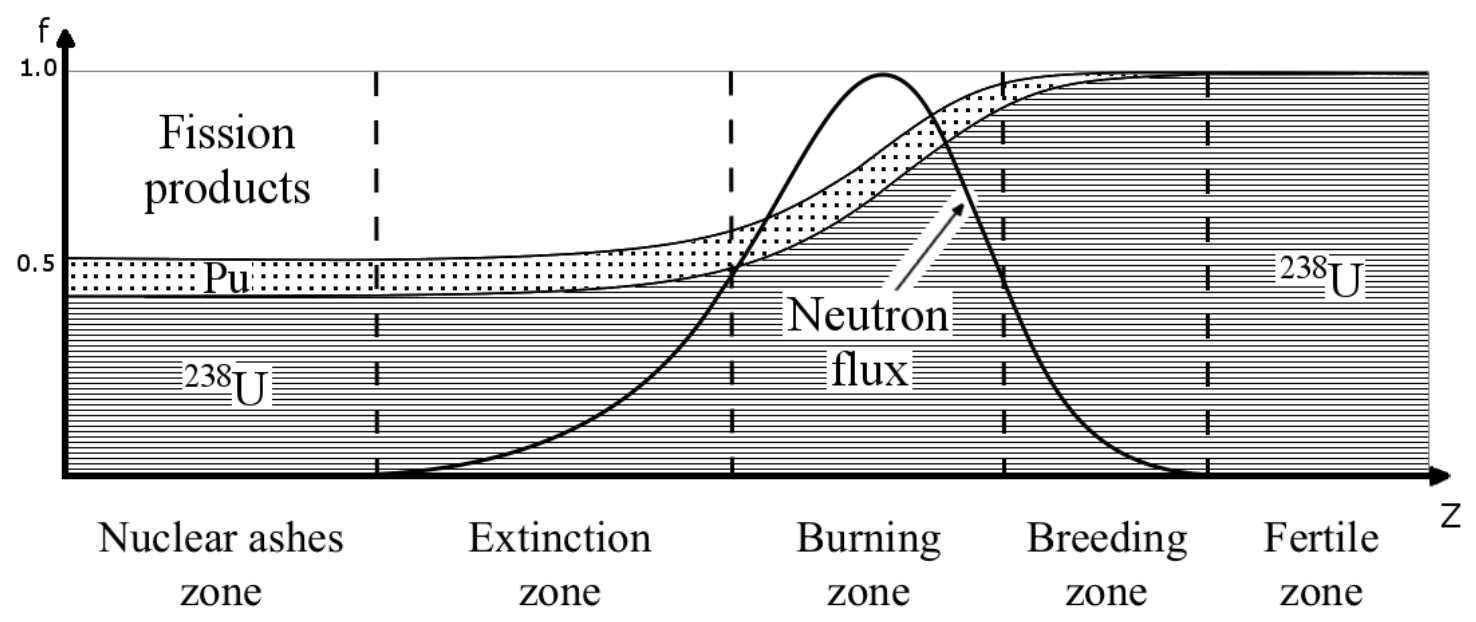

Figure. The nuclear burning wave propagation from left to right in the pure ${ }^{238} \mathrm{U}$ medium. f denotes the volume fractions of fuel components: pure ${ }^{238} \mathrm{U}$ (area filled with lines), plutonium (area filled with dots) and the fission products (white area). The bold solid curve is the neutron flux distribution. All curves are the result of calculations.

\section{THEORETICAL APPROACHES FOR NBW DESCRIPTION}

Feoktistov's analytical approach and criterion of the NBW existence

The problem that Feoktistov set himself was to find out whether such a self-sustaining regime is possible and, if so, to determine the conditions for its existence. In an attempt to solve this problem analytically, Feoktistov was forced to simplify his mathematical model as much as possible, highlighting the main factors and omitting the secondary ones.

He first considered the processes in a semi-infinite fuel region, consisting of pure ${ }^{238} \mathrm{U}$ and irradiated from the open border with neutrons. As a result of the $(\mathrm{n}, \gamma)$ reaction, the nuclide ${ }^{239} \mathrm{U}$ is produced, and after two beta decays it turns into ${ }^{239} \mathrm{Pu}$ via an intermediate nuclide ${ }^{239} \mathrm{~Np}$ :

$$
{ }^{238} \mathrm{U}+n \rightarrow^{239} \mathrm{U} \longrightarrow{ }_{\beta}^{239} \mathrm{~Np} \underset{\beta}{\longrightarrow}{ }^{239} \mathrm{Pu}
$$

In this case, the concentration of ${ }^{239} \mathrm{Pu}$ in the medium $N_{P u}$ is determined by two opposite processes: production and burnup, and can be described by the following equation:

$$
\frac{d N_{P u}}{d t}=n v_{n}\left(\sigma_{a 8} N_{8}-\left(\sigma_{a}+\sigma_{f}\right)_{P u} N_{P u}\right),
$$

where $n$ and $v_{n}$ are the concentration and velocity of neutrons, $\sigma_{a 8}$ is the neutron absorption cross-section for ${ }^{238} \mathrm{U}$, $N_{8}$ is the concentration of ${ }^{238} \mathrm{U}$ nuclei, $\sigma_{a . f}$ are the absorption and fission cross-sections for ${ }^{239} \mathrm{Pu}$ nuclei and $N_{P u}$ is the ${ }^{239} \mathrm{Pu}$ concentration. Basing on this equation, Feoktistov introduced a parameter of the equilibrium plutonium concentration $\tilde{N}_{P u}$, assuming the change of the ${ }^{239} \mathrm{Pu}$ concentration in (2) to be zero: 


$$
\tilde{N}_{P u}=\frac{\sigma_{a 8}}{\left(\sigma_{a}+\sigma_{f}\right)_{P u}} N_{8} .
$$

The physical meaning of this parameter is quite simple: it is such a concentration of plutonium to which the system approaches when it is left to itself under a persistent neutron irradiation.

Another important parameter of the problem is the critical concentration of ${ }^{239} \mathrm{Pu}$ in this medium $N_{c}$, which provides a constant value of the neutron concentration in the system or, in other words, this means that the so-called neutron multiplication coefficient $k_{\text {eff }}$ is equal to unity. This parameter can be obtained from the neutron balance equation:

$$
\frac{d n}{d t}=n v_{n}\left((v-1) \sigma_{f P u} N_{P u}-\sum_{i} \sigma_{a i} N_{i}\right)
$$

by equating the derivative $d n / d t$ to zero. Here, $v$ is the number of fission neutrons. Thus, the expression for the critical concentration of plutonium $N_{c}$ is

$$
N_{c}=\frac{\sum_{i} \sigma_{a i} N_{i}}{(v-1) \sigma_{f \mathrm{Pu}}}
$$

If $N_{P_{u}}=N_{c}$, it means that the system stays in the exact critical state with constant neutron concentration and energy production as well. If $N_{P u}>N_{c}$, then the system will be above-critical ( $k_{\text {eff }}>1$ ) and the chain reaction will occur, while the neutron concentration will increase exponentially. Otherwise, at $N_{P u}<N_{c}$, the system will be subcritical and the neutron flux will decrease quickly without an external neutron source.

Since expressions (3) and (5) for the parameters $\tilde{N}_{P u}$ and $N_{c}$ show different dependences on the cross sections and nuclide concentrations, in principle, various realizations of the relation between these two parameters are possible.

If $\tilde{N}_{P_{u}}<N_{c}$ is fulfilled, that takes place, in particular, for the nuclear system with the thermal neutron spectrum $[2,3]$, then the critical state cannot be achieved without an external neutron source, and a self-sustained nuclear burning process is impossible.

In case of the fast neutrons, we have $\tilde{N}_{P u}>N_{c}$, which creates conditions for the chain reaction being sustained. In a literal sense, it means that the plutonium concentration tends to its equilibrium value exceeding the critical one. This fact looks dangerous as it means that the reactor might go into an explosive chain reaction. But at the same time a neutron lifetime in the core $\left(\tau=l / v_{n} \sim 10^{-8} s\right)$ is much smaller than the time of plutonium creation (2.4 days), thus an entire excess plutonium will be burned out before the reactor goes into an "explosive" state. It is just this property which is usually referred to as an intrinsic safety.

Further in his articles, Feoktistov considers equations of the neutron diffusion and fuel burn-up describing the simplest variant of reactor which consists of ${ }^{239} \mathrm{Pu},{ }^{238} \mathrm{U}$, and only one intermediate nuclide ${ }^{239} \mathrm{U}$, which effectively represents the two intermediate nuclides in (1). This set of equations is considered in the one-dimensional geometry and in the one neutron-energy group approximation under the assumption that the absorption cross-section values are equal for all involved nuclides, including the fission products, which made it possible to reduce all needed neutron reaction cross-sections to only two material constants, namely, to $\tilde{N}_{P_{u}}$ and $N_{c}$. Then, assuming that the NBW mode exists, and making the corresponding Galilean transformation $\left(x^{\prime}=x+V t\right)$, i.e., passing into the co-moving frame of reference moving with the wave velocity $V$, these equations were solved for the case of the steady-state nuclear burning wave moving along the considered infinite ${ }^{238} \mathrm{U}$ medium with a constant velocity. This allowed Feoktistov to find the solution in a self-similar form depending only on the space variable $x^{\prime}$ in the co-moving frame. From this consideration, Feoktistov described the main features of the steady-state NBW regime, and one of the largest achievements of this work was the formulation of a simple criterion $\tilde{N}_{P_{u}}>N_{c}$, which provides the feasibility of functioning of a NBW reactor.

Further it was pointed out that it could be also possible to implement such a reactor for the ${ }^{232} \mathrm{Th}-{ }^{233} \mathrm{U}$ fuel cycle. The problems of the huge thermal energy release that were mentioned by Feoktistov are still actual.

In the context of discussing the Feoktistov approach, it is worth to mention the work [4] by V. Pilipenko et al., in which the NBW mode was studied in the framework of the Feoktistov model on the basis of both the analytical analysis in the steady-state-solution approach, which was described in detail, and of the simulation of the initiation and evolution of the NBW by numerically solving the non-stationary problem for the set of Feoktistov's equations. In particular, a 
consideration was given to the NBW realization with the use of an external neutron source, accompanying and irradiating the moving nuclear burning area, under the conditions when the NBW mode would be impossible without this source.

\section{Goldin's and Anistratov's approach for numerical calculations}

Goldin and Anistratov $[5,6]$ further developed Feoktistov's approach trying to solve numerically an evolutionary problem. In their work, they used 16 fissile isotopes and three groups of fission products. They also take into account the presence of coolant and structural materials in the fast reactor core. To describe the neutron processes in the reactor they used the neutron transport, neutron kinetics and fuel-burnup equations. In their approach, the non-stationary equation of neutron transport was considered in the one-group diffusion approximation. The one-group constants were calculated using an averaging spectrum function derived from solving the multi-group homogenous model for initial stationary reactor assembly.

To describe the reactor criticality, it is convenient to use the reactivity $\rho=\left(k_{\text {eff }}-1\right) / k_{\text {eff }}$ or the reactor time parameter $\lambda$. The parameter $\lambda$ is introduced into the equations by assuming the exponential dependence of the fluxes on time:

$$
\phi(\vec{r}, t)=\phi(\vec{r}) e^{\lambda t}
$$

By using this expression in the non-stationary multi-group and effective one-group set of diffusion equations, while taking into account the delayed neutrons, it is possible to get equations for the determination of $\lambda$, group scalar and vector fluxes. It is also possible to get the reactor time constant from solving the non-stationary transport and kinetics equations:

$$
\lambda=\frac{d}{d t}\left(\ln \left(\int_{G} \psi d \vec{r}\right)\right)
$$

here $G$ is the solution region of the problem.

Goldin and Anistratov solved the above-mentioned equations using numerical calculations. The results show, that such a type of reactor is stable against considerable perturbations. According to the claim of the authors, the wave will be propagating during one year, after which the wave will start to decay. It should be mentioned, that these results were obtained without recalculating the averaged one-group cross-sections with the change of the space-energy distribution of the neutron flux.

\section{Teller's Monte Carlo simulations calculations}

Edward Teller [7, 8] with his team used Monte-Carlo-method based calculations to simulate the neutron-induced reactions and neutron transport in the fast reactor operating in the mode they called as a nuclear deflagration wave in their work. In their work, they used TART95 program package for modeling processes occurring in this reactor. In the initial assembly, the fuel in the main region of the reactor core was composed of ${ }^{232} \mathrm{Th}$, while in the ignition region, where the nuclear burning was initiated, it was $10 \%$ enriched by ${ }^{235} \mathrm{U}$. For the simulation, the TART95 mode with 175 neutron-energy groups was used. In the calculations, the presence of several other nuclides was also taken into account, representing actinides, construction materials, coolant, fission products and neutronic poisons.

The authors of the paper claimed some results based on their simulation. It was found that the ${ }^{232} \mathrm{Th}$ fuel burned well with possible generation of power around $1 \mathrm{GW}$ in the case of the fuel cylinder of diameter less than 1 meter. The fuel burnup can be achieved in the range from $10 \%$ to $50 \%$ (which confirms Feoktistov's predictions). There is possibility to make NBW-reactor thermostatic by internal physics. They proposed also a scheme of automatic thermostatic and reactor power control by using ${ }^{6} \mathrm{Li}$ as a neutron absorber in the core. Their simulation predicts a relatively small total mass $(<0.1$ ton) of the fissile material in the ignition zone.

In general, their work showed quite promising results for the considered NBW-reactor.

\section{Sekimoto's CANDLE burnup strategy}

The work performed in the Tokyo Institute of Technology by Hiroshi Sekimoto and his team $[9,10]$ is directed toward study of the NBW reactor. In their works it is called CANDLE as the acronym standing for "Constant Axial shape of Neutron flux, nuclide densities and power shape During Life of Energy production". Like Feoktistov, the Sekimoto group used the Galilean transformation $z^{\prime}=z+V t$ to the accompanying co-moving frame to consider steadystate solutions in the form of the NBW for the stationary neutron balance (diffusion) equation and the set of nuclide balance equations, describing the system under consideration. For solving these equations, an iteration procedure was proposed. To find the optimal velocity $V$ of movement of the nuclear burning region, in the course of these iterations Sekimoto used the following iteration formula: 


$$
V^{(i+1)}=V^{(i)} V^{(i-1)} \frac{\Delta z_{C}^{(i)}-\Delta z_{C}^{(i-1)}}{\Delta z_{C}^{(i)} V^{(i)}-\Delta z_{C}^{(i-1)} V^{(i-1)}}
$$

Here, $\Delta z_{C}^{(i)}=z_{C}^{(i)}-z_{C}^{(i-1)}$ is the shift of the neutron flux distribution center during successive iterations. This scheme required a good initial guess of the $V^{(1)}$ and $V^{(2)}$ values. The iterations were performed until the distributions of the calculated neutron flux and nuclide densities stopped to move along z-axis.

The numerical calculations for solving the obtained equations were performed using 21-group approximation. The needed cross-sections were taken from the JENDL-3.2 library. The nuclide transformation chains comprised 20 fissile nuclides and 66 fission products nuclides. The fertile fuel in this reactor was ${ }^{238} \mathrm{U}$ and the reactor had the cylindrical geometry with 8 meters in length and with the radius of 2 meters. The found neutron flux was normalized to have $3 \mathrm{GW}$ power output.

As a result of the simulations, a steady-state self-similar neutron distribution was shown to be moving at the velocity of $4 \mathrm{~cm} / \mathrm{yr}$. The burnup depth in the spent fuel behind the NBW was around $40 \%$, which is much higher than in traditional reactors. This work is important since it showed the possibility of the NBW implementation in the ${ }^{238} \mathrm{U}$ fuel basing on the fairly realistic theoretical model. It is also important to note that the Tokyo group used two-dimensional models and wide range of nuclides.

In a large number of subsequent works based on the approach described above, Sekimoto with co-authors considered the possibility of various options for implementing the CANDLE burnup strategy by varying the use of different coolants ( $\mathrm{Na}, \mathrm{Pb}, \mathrm{Pb}-\mathrm{Bi}$ eutectic, gas), sizes and compositions of the core, reactor power, and other parameters. However, since the calculation scheme which they use in these works is based on the self-similar solution to the problem, it is impossible to study transient processes in such a reactor and to study the stability of the NBW mode within the framework of this mathematical approach.

\section{Hugo van Dam analytical considerations and its modifying by Chen and Maschek}

An original model of the NBW reactor was developed by Hugo van Dam in papers [11,12], where he called this mode as the criticality wave. In his work, the set of several fuel burnup equations was replaced by the effective burnup function $k_{\infty}(\psi)$ and the feedback coefficient $\gamma$ as an arbitrary parameter. These substitutions are then included in the neutron balance equation. To get analytical solutions, Hugo van Dam also considered a quasistatic approximation, which is possible due to the fact that the neutron diffusion occurs much faster than the process of propagation of the criticality wave. Using the Galilean transformation of coordinates $\xi=x+V t$, he obtains the following equation for the scalar neutron flux $\phi(\xi)$ :

$$
L_{0}^{2} \frac{d^{2} \phi}{d \xi^{2}}+\left[k_{\infty}(\psi)-1+\gamma \phi\right] \phi=0
$$

where $\psi$ is the neutron fluence and $L_{0}$ is the diffusion length.

By selecting the burnup function in a simple (parabolic) form, which is close to the real one, and certain feedback coefficient values, it is possible to obtain analytical solutions of the neutron balance equation. Despite the seeming simplicity of this model, it was able to predict some characteristics of the behavior of the NBW reactor.

Results of the analytical model solution show that the burning wave can exist only in the case of a negative feedback coefficient and when the following ignition condition is fulfilled:

$$
2 k_{\max }+k_{0}>3
$$

Here $k_{\max }$ and $k_{0}$ are the maximum and initial values of the chosen burnup function. The velocity of such a wave is proportional to the maximum neutron flux density which is determined through the feedback coefficient and burnup function.

Hugo van Dam also performed numerical calculations for the developed model. This part of the work was done to determine the burning wave ignition characteristics and to consider possibility of a power control in such a reactor. It was shown that an external neutron source should have certain optimal strength and duration to initiate a self-sustained wave propagation. The power control is possible by changing the feedback coefficient value. Choosing different burnup function gives different results for the total fuel burnout and wave velocity.

In the work of X.-N. Chen and W. Maschek [13] this approach was modified by means of using an original perturbation method and the radial buckling approximation, that gave them an opportunity to reduce the initially threedimensional problem to a one-dimensional one taking into account a transverse neutron leakage. Later in [14] they used 
this calculation scheme for description of the pebble-bed type reactor, in which, de facto, the fuel moves with the NBW velocity through a stationary reactor (see also Sekimoto's book [10]). Such a concept of "standing burning wave" is a full analogue of the "running" NBW from the physical point of view, but may have some constructive advantages for its practical realization.

\section{Khotyayintsev et al. NBW velocity study}

In works $[15,16]$ by Khotyayintsev et. al., behaviour of the NBW velocity, as an important characteristic of the NBW mode, was studied depending on a number of parameters of the reactor model in the framework of a planar onedimensional model, basing on the neutron diffusion equation together with the equations of burn-up of the U-Pu fuel components including 9 nuclides as well as the fission products in the one-group approximation. A possibility of burning out of a part of the fission products was also admitted. The authors also studied the influence of a temperature feedback of not specified origin in the simplest model form by including a corresponding term with an arbitrary thermal feedback coefficient in the diffusion equation. Analogously to the Feoktistov approach, the solution of this set of equations was sought in the form of a steady-state wave moving with a constant velocity along a reactor of infinite length.

According to the aforesaid, the authors presented the neutron diffusion equation in the following general dimensionless form:

$$
\frac{d^{2} \phi}{d z^{2}}+g \cdot \phi=0, \quad g=\sum_{i} c_{i} N_{i}-p+\gamma w \phi\left(\sum_{i} c_{a i} N_{i}+p\right)
$$

Here $N_{i}$ are the dimensionless nuclear densities that obey the fuel burn-up equations, $c_{i}$ and $c_{a i}$ are the dimensionless coefficients that depend on the corresponding microscopic absorption and fission cross sections, $w$ is the dimensionless NBW velocity, $p$ is the effective absorber density which includes the absorption by non-fuel nuclides and, if allowed for, the effect of transverse neutron leakage, $\gamma$ is the phenomenological thermal feedback parameter. By integrating the Eq. (11), the authors studied the conditions for existence of a stationary NBW solution. Numerical calculations with certain values of the problem parameters, allowed authors to solve the diffusion equation along with the burn-up equations and get distributions of the flux and nuclide concentrations in the wave. The authors also proposed and used an analytical approach for obtaining the solutions of the steady-state NBW type basing on the method of successive approximations in which the wave velocity $w$ was considered as a small parameter. This approach allowed them to derive analytical expressions for the dependence of the NBW velocity on the problem parameters, including the arbitrary parameters $p$ and $\gamma$.

From the obtained calculation results, the authors performed a comparison between feedback parameters caused by the thermal and fuel burn-up effects. An interesting result was derived at low NBW velocity values, where authors' calculations showed a bifurcation of the velocity dependence at the same control parameter, which authors attributed to the effect of ${ }^{241} \mathrm{Pu}$ instability. However, only the upper branch of the velocity dependence turned out to have a physical meaning, which indicated existence of a small but finite minimum value of the velocity.

\section{Fomin et al. non-stationary solution of the NBW problem}

The work performed by the Kharkiv group [17-25] was aimed at the study of non-stationary processes occurring in the fast reactor of cylindrical form with two initial homogeneous axial zones (the ignition and breeding ones) at the stages of the NBW initiation and its propagation along the reactor axis in the framework of an original deterministic approach, developed by the authors. This approach is based on numerically solving the non-stationary equations of neutron diffusion in the reactor medium together with the burnup equations for fuel components, which include 10 nuclides, and with the nuclear kinetics equations for the delayed neutron precursors with using realistic nuclear constants and cross sections. The authors have developed original packages of computer programs to perform numerical calculations for solving this non-stationary evolution problem. The needed realistic nuclear data were obtained from the BNAB Nuclear Data Library $[26,27]$ in the 26 neutron-energy group approximation. The fuel in the breeding zone is composed of the fertile ${ }^{238} \mathrm{U}$ (the variants with ${ }^{232} \mathrm{Th}$ fuel and the mixed of $\mathrm{U}-\mathrm{Th}$ fuel were also considered), the fuel in the ignition zone consists of ${ }^{238} \mathrm{U}$ enriched by $10 \%$ of ${ }^{239} \mathrm{Pu}$.

First the authors used a simplified model [17-20], where the transverse neutron leakage was either neglected $[17,18]$ or it was described by employing the radial buckling approximation $[19,20]$. These calculations were performed in the so-called effective multigroup diffusion approximation, where the problem was reduced to a nonstationary one-group problem with making use of effective neutron-nucleus cross-sections averaged by the local neutron spectra found from the corresponding stationary multigroup criticality problem for the current time moment, which allows one to effectively take into account the changes in the cross sections according to variations of the energyspace distribution of the neutron flux. According to this approach, it is possible to write down the one-group nonstationary diffusion equation using the radial buckling concept taking into account delayed neutrons in the following form: 


$$
\frac{1}{v_{n}} \frac{\partial \Phi}{\partial t}-\frac{\partial}{\partial z} D \frac{\partial \Phi}{\partial z}+D B_{r}^{2} \Phi+\Sigma_{a} \Phi-(1-\bar{\beta})\left(v_{f} \Sigma_{f}\right) \Phi=\sum_{i} \sum_{l} \lambda_{l}^{i} C_{l}^{i}
$$

where $v_{n}$ is the neutron velocity, $\Phi$ is the scalar neutron flux, $\Sigma_{f}$ and $\Sigma_{a}$ are effective macroscopic absorption and fission cross-sections, $D=1 / 3 \Sigma_{\mathrm{tr}}$ is the diffusion coefficient, $v_{f}$ is the mean number of neutrons produced per nucleus fission, $\bar{\beta}$ is the effective fraction of delayed neutrons, $C_{l}^{i}$ and $\lambda_{l}^{i}$ are the concentration and decay constant of precursor nuclei of the $i$-th group for the $l$-th fissile nuclide.

The important results of these studies are that they proved the feasibility of initiating and using the NBW mode in the nuclear reactor with the fuel of the U-Pu cycle, as well as revealed a number of essential details of the NBW evolution course, in particular the dependence of the NBW velocity on the radius of the reactor core was studied and a critical radius at which the wave cannot propagate was found. However, the results obtained for the reactor based on the ${ }^{232} \mathrm{Th}$ fuel showed serious difficulties in implementing the NBW mode, which had suggested appropriateness of further consideration of variants of the NBW reactor with mixed fuel composed of both with ${ }^{238} \mathrm{U}$ and ${ }^{232} \mathrm{Th}$ at roughly equal concentrations.

The shortcomings of using the radial buckling is that it gives an approximate allowance for the radial neutron leakage and ignores the effects of radial non-uniformity of the burnup of fuel components. Moreover, it does not allow one to describe reactor systems with any radial inhomogeneity, for example, in the presence of the radial neutron reflector, and in these cases it is necessary to consider the exact two-dimensional (2D) cylindrical problem of neutron transport in the reactor under discussion. Such a $2 \mathrm{D}$ problem with using the exact 26 neutron-energy groups approach has been further considered by the authors [21] for a simple cylindrical reactor model with a single radial zone without the radial reflector. The comparison between the results of calculations in these two approaches $[16,17]$ and $[18]$ has shown that the simplified calculations with the radial buckling and effective multigroup approximation give a reasonable qualitative description of the NBW evolution but with some quantitative discrepancies with the exact 2D multigroup approach [21]. However, the calculations in the exact approach [21] are rather time-consuming and require much more computational resources. For this reason, in the works [22-25] the authors used the simplified approach, similar to that of papers $[19,20]$, for further studying different issues concerning the NBW initiation and propagation in the cylindrical reactor variants with the metal fuel of both U-Pu and mixed Th-U-Pu fuel cycle. In these works, they analyzed different transient processes in the NBW reactor and investigated the NBW mode stability (see [24]). The used non-stationary approach allowed Fomin's group to study the startup behaviour of the NBW reactor and the conditions for realizing a "smooth" startup with parameters acceptable from the practical point of view $[23,25]$, which is an important problem. Besides, the authors studied the features of processes of the forced temporary shutdown of the NBW reactor and further restarting the NBW mode [25].

\section{Study of standing NBW by Yu. Leleko, V. Gann, and A. Gann}

In the papers of Yu. Leleko, V. Gann, A. Gann $[28,29]$ the concept of the nuclear burning standing wave (NBSW) in the neutron multiplication medium is considered. From the point of view of the physics of neutron-nucleus processes, this concept is analogous to Feoktistov's nuclear burning wave, in which instead of the self-sustained process of the NBW propagation in the stationary neutron-multiplication medium (fertile ${ }^{238} \mathrm{U}$ ), the fertile material is considered to be moving with the NBW propagation velocity, so that the active burning area were not moving relative to the reactor vessel. From the mathematical point of view, the only difference is in the transition from the rest frame to the frame which moves with the NBW velocity. In the judgment of the authors of those papers, such a change can essentially simplify the design of reactor as compared to the case of the moving active area in the classical NBW approach. Additionally, it is assumed that slightly changing the velocity of the "fresh" fuel movement, it could be possible to regulate the fuel burnup depth.

A significant difference between the NBSW concept considered in the papers $[28,29]$ and the self-sustained NBW propagation process, where the need of external control of the reactor reactivity is absent, is the fundamental need for such control in the case of NBSW.

In the papers $[28,29]$ the implementation of the NBSW concept is considered in both cylindrical and spherical reactors. In the first case, the NBW should "move" in the radial direction from the cylinder axis, and the fuel $\left.{ }^{238} \mathrm{U}\right)$ moves in the opposite direction, i.e. to the cylinder center, where the spent fuel is continuously being removed from reactor [28]. In the case of spherical geometry, the NBW is to be moving from the center of the sphere to the outside, and the fuel moves from periphery to the center of the spherical reactor, where it is being continuously removed [29]. If the speed of the fuel movement to the center is precisely equal to the velocity of the NBW propagation, we have the NBSW.

In its cylindrical variant, this concept is close to the "standing wave" concept with periodical "shuffling" of fuel assemblies, which was proposed by "Terra Power" [30]. The main difference between them is that in the variant of the reactor from [28] the supply of the fuel is considered to be continuous, while in [30] to shuffle the fuel assemblies the reactor must be stopped. 
The mathematical calculation model that was used in the works $[28,29]$ is based on the solving of the onedimensional diffusion equation together with a maximally simplified set of the burnup equations for the fuel components (only four ones: ${ }^{238} \mathrm{U},{ }^{239} \mathrm{~Np},{ }^{239} \mathrm{Pu}$, and fission products). The transition from the variables of coordinate (radius) and time to the integral variable of fluence, allowed the authors of those papers to obtain an analytical expressions for the stationary approximation of the NBW, which can be used to analyze the dependence of the radial neutron distribution on the problem parameters. The performed analysis showed the possibility of the existence of the radial and cylindrical standing waves of nuclear burning for some parameters of considered systems.

In those papers, a comparison between results calculated with the analytical expressions and by numerical calculations of such a reactor with the MCNPX code was performed, which showed their quite good agreement. Such a powerful computation instrument as the MCNPX code, which is based on the Monte-Carlo method for the simulation of neutron-nucleus processes simulation in the three-dimensional geometry, has wide possibilities for taking into account the complex nuclide composition of the reactor core, including not only the extended nuclear transformation chain of fuel components, but also the presence of the coolant and construction materials in the core of the reactor. Unfortunately, in those papers there is no data about calculations for more realistic component compositions, which may sufficiently influence not only the numerical results, but also some of the conclusions of those papers.

In addition, we should mention one more feature of using the MCNPX code, which has been developed for modeling processes in reactors of the conventional type with the external reactivity control that is realized by using control rods. The matter is that when simulating with MCNPX, the reactor power is a parameter that is set externally and is kept constant automatically. At the same time, the power of the reactor operating in the steady-state NBW mode is an internal self-consistent parameter of the system, which is determined only by the initial composition of the system and its size.

\section{CONCLUSIONS}

This article provides an overview of a number of the most significant works on the problem of a nuclear burning wave reactor. Using various approaches and calculation models, in general, the authors of these studies have proven the fundamental possibility of implementing the NBW mode. The considered papers also investigate the most important characteristics of a nuclear burning wave, such as the propagation velocity, energy density, the power dependence on various parameters of the reactor, the problems of start-up, forced shutdown and restart of the reactor.

The reactor operating in the NBW mode has very attractive features, such as:

- the absence of the need for operational control of reactivity, which significantly reduces the role of the "human factor" in the reactor control;

- the property of "intrinsic safety", provided by the presence of a specific mechanism of negative reactivity feedback;

- the possibility of using natural or depleted uranium and thorium as the main fuel, capable of solving the problem of providing the Mankind with relatively cheap energy resources for thousands of years;

- the possibility of using the spent fuel of other reactors, which can help to solve the environmental problem of nuclear waste disposal;

- the absence of the need to reload the fuel throughout the entire reactor campaign reduces the risks of a theft of fissile materials during their transportation, helping to solve the problems of non-proliferation and prevention of nuclear terrorism;

- high fuel burnup depth, and, therefore, high efficiency of its use, will allow abandoning the organization of a closed fuel cycle and, thereby, significantly reduce the cost of nuclear energy of the future.

Therefore, if the NBW reactor is implemented, it will be a good candidate for a new generation of nuclear reactors.

However, there are also a number of unsolved problems that impede the speedy implementation of this concept. The main one among them is a high level of radiation damage in the fuel (swelling problem) and cladding materials. According to estimates, they significantly exceed the values that the present-day materials can withstand.

Nevertheless, the continuous progress in the development of new types of nuclear fuel and structural materials, which has been observed in recent years, as well as the search for unconventional constructive solutions (see, for example [30]) inspire confidence that the NBW reactor can become one of the main solutions to the growing world energy needs.

\section{ORCID IDs}

(D)Maksym S. Malovytsia, https://orcid.org/0000-0002-8652-5806; Alex S. Fomin, https://orcid.org/0000-0002-3631-0604

(Dergii P. Fomin, https://orcid.org/0000-0002-1495-0512

\section{REFERENCES}

[1] S.M. Feinberg, in Record of Proceedings: Session B-10, Int. Conf. on the Peaceful Uses for Atomic Energy. (Geneva, Switzerland: United Nations, 1958), 9(2), 447.

[2] L.P. Feoktistov, Preprint IAE-4605/4. IAE, Moscow, (1988).

[3] L.P. Feoktistov, Dokl. Akad. Nauk SSSR, 309, 864 (1989).

[4] V. Pilipenko, D. Belozorov, L. Davydov, N. Shul'ga, in CD: Proceedings of ICAPP 03, (Cordoba, Spain, May 4-7, 2003), Paper 3169.

[5] E. Teller, M. Ishikawa, L. Wood, et al. In: Int. Conf. on Emerging Nuclear Energy Systems, 1 (1996). 
[6] E. Teller, Preprint UCRL-JC-129547, LLNL, Livermore, CA, USA (1997).

[7] H. Sekimoto, K. Ryu, Y. Yoshimura, Nuclear Science and Engineering. 139, 306-317 (2001), https://doi.org/10.13182/NSE01-01.

[8] H. Sekimoto, Light a CANDLE: New Burnup Strategy, (Tokyo Institute of Technology, Tokyo, 2005).

[9] V.Ya. Goldin and D. Yu. Anistratov, Mathematical Modelling, 7, 12 (1995).

[10] V.Ya. Goldin, N.V. Sosnin, Yu.V. Troshchiev, Dokl. Ros. Acad. Nauk., 358, 747-748 (1998). (in Russian).

[11] Hugo van Dam, Annals of Nuclear Energy, 27, 1505 (2000), https://doi.org/10.1016/S0306-4549(00)00035-9.

[12] Hugo van Dam, Annals of Nuclear Energy, 30, 1495-1504 (2003), https://doi.org/10.1016/S0306-4549(03)00098-7.

[13] X.-N. Chen, and W. Maschek, Annals of Nuclear Energy, 32, 1377-1390 (2005). https://doi.org/10.1016/j.anucene.2005.01.012.

[14] X.-N. Chen, E. Kiefhaber, and W. Maschek, Progress in Nuclear Energy. 50, 219-224 (2008). https://doi.org/10.1016/j.pnucene.2007.11.064.

[15] V.M. Khotyayintsev, V.M. Pavlovych, and O.M. Khotyayintseva, In: Proceeding of Int. Conf. "Advances in Reactor Physics to Power the Nuclear Renaissance" (PHYSOR 2010), (Pittsburgh, PA, USA, 9-14 May 2010).

[16] V.M. Khotyayintsev, A.V. Aksonov, O.M. Khotyayintseva, V.M. Pavlovych. V. Gulik, and A.H. Tkaczyk, Annals of Nuclear Energy. 85C, 337 - 345 (2015). https://doi.org/10.1016/j.anucene.2015.04.044.

[17] S. Fomin, Yu. Mel'nik, V. Pilipenko, and N. Shul'ga, Annals of Nuclear Energy. 32, 1435 (2005). https://doi.org/10.1016/j.anucene.2005.04.001.

[18] S. Fomin, Yu. Mel'nik, V. Pilipenko and N. Shul'ga, In: Nuclear Science and Safety in Europe, p. 239, Springer, the Netherlands (2006), https://doi.org/10.1007/978-1-4020-4965-1_20.

[19] S. Fomin, Yu. Mel'nik, V. Pilipenko and N. Shul'ga, Problems of Atomic Science and Technology. Series: Nuclear Physics Investigations. 3, 156 (2007), https://vant.kipt.kharkov.ua/TABFRAME_poisk_c.html

[20] S. Fomin, Yu. Mel'nik, V. Pilipenko and N. Shul'ga, Progress in Nuclear Energy. 50, 163 (2008), https://doi.org/10.1016/j.pnucene.2007.10.020.

[21] S.P. Fomin, A.S. Fomin, Yu.P. Mel'nik, V.V. Pilipenko, N.F. Shul'ga, In CD: Proc. of 1st Int. Conf. “Global 2009” (Paris, France, 2009), Paper 9456.

[22] S.P. Fomin, O.S Fomin., Yu.P. Mel'nik, V.V. Pilipenko, N.F. Shul'ga, Progress in Nuclear Energy. 53, $800-805$ (2011). https://doi.org/10.1016/j.pnucene.2011.05.004.

[23] O.S. Fomin, S.P. Fomin, Yu.P. Mel'nik, V.V. Pilipenko, and N.F. Shul'ga, Journal of Kharkiv National University, physical series «Nuclei, Particles, Fields», 58(2), 49-56 (2013), https://periodicals.karazin.ua/eejp/article/view/13512.

[24] S.P. Fomin, A.S. Fomin, Yu.P. Mel'nik, V.V. Pilipenko, N.F. Shul'ga, in: Topical Issues in Fast Reactors and Related Fuel Cycles, (Proc. Conf. FR-13, Paris, 2013), IAEA, Vienna, 2014, Contributed Paper IAEA-CN-199-457, 10 p., http://wwwpub.iaea.org/MTCD/Publications/PDF/SupplementaryMaterials/P1665CD/Track3_Safety.pdf.

[25] O.S. Fomin, S.P. Fomin, Yu.P. Mel'nik, V.V. Pilipenko, N.F. Shul'ga, in: Proc. of Int. Conf. “Global 2015” (Paris, France, 2015), Paper 5254.

[26] L.P. Abagyan, N.O. Bazazjanc, I.I. Bondarenko, and M.N. Nikolaev, Group Constants for Calculations of Reactor and Shielding, (Energoizdat, Moscow, 1981) pp. 231. (in Russian).

[27] I.I. Bondarenko, et al. Group Constants for Nuclear Reactor Calculations. (Consultants Bureau Inc., New York, 1964).

[28] Yu.Y. Leleko, V.V. Gann, A.V. Gann, Problems of Atomic Science and Technology. 2 (108), 138-143 (2017).

[29] Yu.Y. Leleko, V.V. Gann, A.V. Gann, Problems of Atomic Science and Technology. 5 (123), 18-24 (2019).

[30] J. Gilleland, R. Petroski, and K. Weaver, Engineering, 2, 88-96 (2016), https://doi.org/10.1016/J.ENG.2016.01.024.

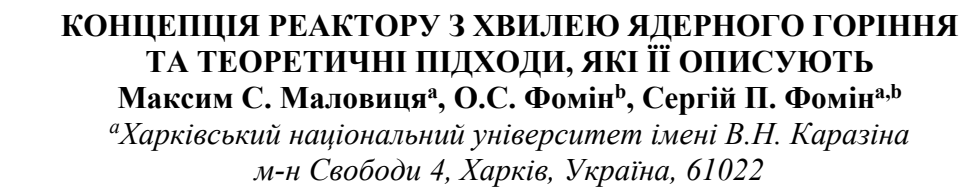

${ }^{b}$ Національний науковий центр «Харківський фізико-технічний інститут»» вул. Академічна 1, Харків, Україна, 61108

Після двох великих аварій на атомних електростанціях у Чорнобилі (1986) та Фукусімі (2011) однією з головних вимог до ядерної енергетики стало забезпечення безпеки як діючих, так і нових реакторів четвертого покоління, що розроблюються зараз. Однією з таких вимог є наявність механізму «внутрішньої безпеки», який робить неконтрольований розгін реактора неможливим ні при яких обставинах, причому, втілення такого механізму повинно бути забезпечене на рівні фізичних принципів, які закладені в конструкцію реактора. Наступною важливою проблемою ядерної енергетики $\epsilon$ необхідність переходу на широкомасштабне використання реакторів-бридерів на швидких нейтронах, за допомогою яких можливо налаштувати розширене виробництво ядерного палива $\mathrm{i}$, таким чином, вирішити проблему забезпечення людства відносно дешевою енергією на тисячі років. Крім того, не вирішеною на сьогодні проблемою є утилізація відпрацьованого ядерного палива, в складі якого є радіонукліди з великим періодом напіврозпаду, що становить довгострокову екологічну загрозу. Однією з перспективних концепцій реактора-бридера на швидких нейтронах, який здатен, у випадку реалізації, частково або навіть повністю вирішити проблеми ядерної енергетики, які були наведені вище, $є$ реактор, що працює в режимі хвилі ядерного горіння, також відомий під назвами «Реактор на рухомій хвилі», CANDLE і деякими іншими. У цій роботі представлений короткий огляд основних теоретичних підходів, які використовуються для опису такого фізичного явища, як хвиля повільного ядерного горіння (дефлаграція) у середовищі, що мультиплікує нейтрони, яке початково складається з фертильного матеріалу урану-238 або торію-232. Проведений порівняльний аналіз можливостей різноманітних математичних моделей для опису цього явища, які побудовані як на детерміністичному підході (тобто розв'язанні рівняння транспорту нейтронів), так і моделей 3 використанням метода Монте-Карло. Обговорюються основні переваги швидкого реактора-бридера, що працює в режимі хвилі ядерного горіння, а також проблеми, які пов'язані з практичним втіленням концепції, яка розглядається.

КЛЮЧОВІ СЛОВА: ядерна енергетика, швидкий реактор, напрацювання та спалювання, хвиля ядерного горіння, реактор рухомої хвилі 


\author{
КОНЦЕПЦИЯ РЕАКТОРА С ВОЛНОЙ ЯДЕРНОГО ГОРЕНИЯ \\ И ТЕОРЕТИЧЕСКИЕ ПОДХОДЫ, КОТОРЫЕ ЕЁ ОПИСЫВАЮТ \\ Максим С. Маловица ${ }^{\mathrm{a}}$, А.С. Фомин ${ }^{\mathrm{b}}$, Сергей П. Фомин ${ }^{\mathrm{a}, \mathrm{b}}$ \\ ${ }^{a}$ Харьковский национальный университет имени В.Н. Каразина \\ пл. Свободы 4, Харьков, Украина, 61022 \\ ${ }^{b}$ Национальный научный центр «Харьковский физико-технический институт» \\ ул. Академичная 1, Харьков, Украина, 61108
}

После двух крупных аварий на атомных электростанциях в Чернобыле (1986) и Фукусиме (2011) одним из главных требований к ядерной энергетике является обеспечение безопасности как действующих, так и разрабатываемых в настоящее время новых реакторов четвертого поколения. Одним из таких требований является наличие механизма так называемой «внутренней безопасности», который делает неконтролируемый разгон реактора невозможным ни при каких обстоятельствах, причем, осуществление такого механизма должно обеспечиваться на уровне физических принципов, заложенных в конструкцию реактора. Следующей важной проблемой ядерной энергетики является необходимость перехода на широкомасштабное использование реакторов-бридеров на быстрых нейтронах, с помощью которых можно наладить расширенное воспроизводство ядерного топлива и, тем самым, решить проблему обеспечения человечества относительно дешевой энергией на тысячи лет. Кроме того, нерешенной на сегодня проблемой является утилизация отработавшего ядерного топлива, в составе которого есть радионуклиды с большим периодом полураспада, представляющие собой долговременную экологическую угрозу. Одной из многообещающих концепций реактора-бридера на быстрых нейтронах, способного в случае реализации частично или даже полностью решить перечисленные выше проблемы ядерной энергетики, является реактор, работающий в режиме волны ядерного горения, известный также под названиями «Реактор бегущей волны», CANDLE и некоторыми другими. В настоящей работе представлен краткий обзор основных теоретических подходов, используемых для описания такого физического явления, как волна медленного ядерного горения (дефлаграция) в нейтроно-мультиплицирующей среде, изначально состоящей из фертильного материала урана-238 или тория-232. Проведен сравнительный анализ возможностей различных математических моделей для описания этого явления, основанных как на детерминистском подходе (т.е. решении уравнения транспорта нейтронов), так и моделей с использованием метода Монте Карло. Обсуждаются основные достоинства быстрого реактора-бридера, работающего в режиме волны ядерного горения, а также проблемы, связанные с практической реализацией рассматриваемой концепции. КЛЮЧЕВЫЕ СЛОВА: ядерная энергетика, быстрый реактор, наработка и выгорание, волна ядерного горения, реактор бегущей волны 